\title{
ORGANIZED CRIME OR INDIVIDUAL CRIME? ENDOGENOUS SIZE OF A CRIMINAL ORGANIZATION AND THE OPTIMAL LAW ENFORCEMENT
}

\author{
JUIN-JEN CHANG, HUEI-CHUNG LU, and MINGSHEN CHEN*
}

\begin{abstract}
This article develops a simple but general criminal decision framework in which individual crime and organized crime are coexisting alternatives to a potential offender. It enables us to endogenize the size of a criminal organization and explore interactive relationships among sizes of criminal organization, the crime rate, and the government's law enforcement strategies. We show that the method adopted to allocate the criminal organization's payoffs and the extra benefit provided by the criminal organization play crucial roles in an individual's decision to commit a crime and the way in which he or she commits that crime. The two factors also jointly determine the market structure for crime and the optimal law enforcement strategy to be adopted by a government. (JEL K4)
\end{abstract}

\section{INTRODUCTION}

Organized criminal activities have been regarded as major economic and social issues since the early 1900s. Although there has been, as pointed out by Fiorentini and Peltzman (1995), enormous research interest in the economics of criminal activities, economists have done relatively little work on issues specifically related to the economics of organized crime. We only see that much of the work has been done by following Becker's (1968) framework where the target is the individual agent's allocative choice between legal and illegal

*We are grateful to an anonymous referee who provided with many insightful comments and suggestions in relation to a previous version of this article. Any errors or shortcomings, however, remain our own responsibility. We also thank seminar participants at Institute of Economics, Academia Sinica, and Tunghai University for their helpful discussions.

Chang: Associate Research Fellow, Institute of Economics, Academia Sinica, and Associate Professor, Department of Economics, Fu-Jen Catholic University, Nankang, Taipei 115, Taiwan. Phone 886-227822791 ext. 532, Fax 886-2-27853946, E-mail jjchang@econ.sinica.edu.tw

$\mathrm{Lu}$ : Professor, Department of Economics, Fu-Jen Catholic University, No. 510, Chung Cheng Road, Hsin Chuang, Taipei 242, Taiwan. Phone 886-2-29052718, Fax 886-2-22093475, E-mail ecos1010@mails.fju. edu.tw

Chen: Associate Professor, Department of Finance, National Taiwan University, No. 1, Section 4, Roosevelt Road, Taipei 106, Taiwan. Phone 886-2-33661088, Fax 886-2-23626744, E-mail chen0811@management. ntu.edu.tw activities in the face of different deterrence arrangements. Among the few exceptions, a criminal organization is often thought of as a monopolistic firm, and the theory of monopoly is predominantly used to analyze organized crimes. Schelling (1967), Buchanan (1973), Backhaus (1979), Gambetta and Reuter (1995), and more recently Garoupa (2000) investigate the optimal public policy toward organized crimes through a welfare comparison between a monopoly (organized criminals) and competitive supplies (individual criminals). Given that criminal activities are seen as "social bads," the monopolistic market is considered to be better than a perfectly competitive one, because its "output of crime" is smaller. ${ }^{1}$

The monopolistic model implies that potential offenders have no other criminal choices but are forced to join the criminal organization if they decide to commit a crime. Clearly, it is less than exhaustive in terms of describing agents' choices in relation to criminal behavior. In fact, the criminal

1. Criminologists sometimes include terrorist groups as criminal organizations; therefore, some studies view the criminal organization as a state, within which members undertake their own legal and illegal activities. Following this line of research, Grossman (1995) and Posner (1998) model the Mafia as a competitor of the state in the provision of public goods and services. Skaperdas and Syropoulos (1995) argue that the relationship between the state and a criminal organization is not completely antagonistic. It is often symbiotic, a live-and-let-live arrangement. 
organization may not be monopolistic after all, as argued by Dick (1995) and others. ${ }^{2}$ Criminologists Johnson (1962), Rubin (1973), and Reiss (1986) observe that most criminal organizations are endemic in some particular areas and/or restrictive in some particular illegal businesses. These criminal activities, such as bootlegging, drug dealing, pimping, and prostitution, are often less organized and would be difficult to successfully monopolize. Dick (1995) also points out that prostitution, smuggling, fencing, and narcotics importation often involve substantial competition among downstream suppliers and can hardly be regarded as monopolistic businesses. In other similar studies, Klein and Crawford (1967), Morash (1983), and Sarnecki (1986) conclude that most youths who engage in delinquency are at most street gangsters and cannot be seen as members of a highly structured organization.

In reality, the determination of the market structure for crime should be endogenous, which has notable implications for the optimal crime enforcement policies and crime itself. To recover the conventionally neglected facts and provide a more complete picture regarding organized crime, this article develops a simple but more general model. In this framework, individual and organized crimes are coexisting alternatives to a potential offender, and joining a criminal organization is seen as only one of the agent's rational choices. In deciding whether to join a criminal organization, the methods used to allocate the criminal organization's payoffs and the extra benefits provided by the criminal organization are given serious consideration. They both play crucial roles in determining the sizes of the criminal organizations as well as in influencing the interactive relationship between the market structure for crime and the government's optimal law enforcement.

This study contributes to the existing literature and provides new insights in three respects. First of all, by allowing the agent to choose rationally between engaging in individual or organized crime, we not only endogenize the size of the criminal organization but also explore the factors that deter-

2. Dick (1995), following Williamson's (1979, 1985) approach, propounds that transaction costs, rather than monopoly power, primarily determine the market structure for crime. mine the type (high or low criminal ability) of offenders that enter the criminal organization. A new theoretical attempt is made in terms of providing an explanation to the observation of Anderson (1995): There are considerable variations in personal qualities and values across different criminal organizations. This issue has not previously been addressed in the existing literature.

Second, this article sheds light on the role of the distribution arrangements of the Mafia's criminal payoff in the determination of the equilibrium market structure for crime. Schelling (1960), Tullock (1974), Grossman (1991), Hirshleifer (1991), Skaperdas (1992), and Polo (1995) have expended much effort in answering such questions as: How does a criminal organization divide its endowment among its members? How do the members of the organization engage in rentseeking by investing their efforts in militia and productive activities? This work, however, does not follow this line of research; rather, it seeks to understand how criminal payoff arrangements determine the size of criminal organizations and the market structure for crime.

Two types of payoff sharing schemes, namely, uniform and ability-adherent sharing schemes, are employed to examine the determination of the market structure for crime. Doing this has two advantages. From a micro-perspective, our analysis shows that the different payoff arrangements of a criminal organization will attract the entry of members that differ in quality in terms of criminal skill. More precisely, if the Mafia's payoff is divided uniformly among its members, the Mafia will only be able to attract offenders with relatively low criminal skill to join the organization. Due to the freerider problem, the offenders with relatively higher ability will refuse to join the Mafia to avoid their distinctly high contributions from being shared by others. However, if the criminal organization's method of sharing is in accordance with its members' abilities, the high-ability offenders could be organized by the Mafia. From a macro-perspective, we show that the sharing arrangement within the criminal organization plays a dominant role in the determination of the market structure for crime and, consequently, influences the optimal enforcement strategy of a government. Our findings benefit the formulation of public policies in relation to organized crime. 


\section{FIGURE 1}

The Three-Stage Game Tree

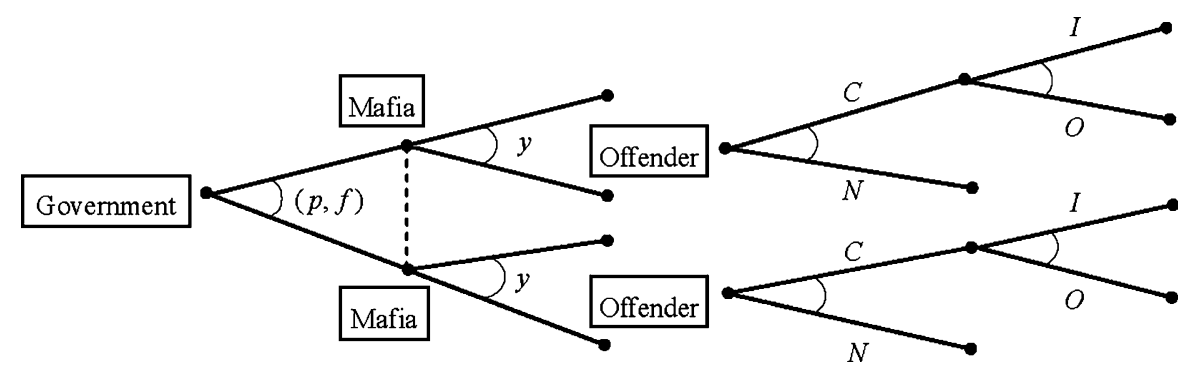

Third, one of the salient features of criminal organizations is that they engage in activities to enhance their influence, improve their businesses, and even reduce the effectiveness of deterrence against them (Abadinsky 1994). Thus, it is believed that there exists an extra benefit for members from joining a criminal organization that is not available to individual criminals. In this article, we model such an extra benefit for the Mafia's members and show that it is another important factor influencing the optimal law enforcement. When the Mafia creates more of these extra benefits for its members, the equilibrium crime rate will rise in response. When there is no extra benefit, the existence of a monopolistic Mafia will result in a reduction in the government's enforcement and, consequently, will become a welfare-improving mechanism within the society, as in the case of the classical view, as espoused by Buchanan (1973) and Garoupa (2000). However, when a positive extra benefit is taken into account, the existence of a monopolistic Mafia is no longer welfare-improving.

The remainder of this article is organized as follows. In section II we describe the scenario by extending Garoupa's (2000) model with the inclusion of the criminal choices in a sequential game. Section III provides equilibria for the three parties, that is, potential offenders, the organization, and the government, in a benchmark model in which the criminal organization adopts a uniform-sharing payoff scheme to distribute its criminal rents. Section IV considers related discussions. In particular, we extend the analysis to an ability-adherent sharing scheme and show that the properties of equilibria in an ability-adherent sharing scheme are different from those in a uniform-sharing payoff scheme. Finally, we conclude in section V.

\section{THE SCENARIO}

The analysis is performed within the framework of a three-stage game. This game consists of three protagonists: the authorities, the criminal organization (the Mafia), and potential offenders. For simplicity, all agents are assumed to be risk-neutral. In a way that departs from the existing literature, the criminal market in our model is not restricted to being perfectly competitive or monopolistic. We emphasize that criminals are in a selfselection market in which all agents make rational decisions regarding participating in organized crime (denoted by $O$ ), engaging in individual crime (denoted by $I$ ), or engaging in no crime at all (denoted by $N$ ).

Figure 1 serves as a supplementary tool to assist us in our exposition. Let us denote $f_{1}$ and $f_{2}$ as the sanctions imposed on the organized and individual criminal offenses, respectively. In the first stage, the government and the Mafia formulate their optimal policies by simultaneous moves, that is, a Cournot-Nash game. The policy maker chooses sanctions $f_{1}$, $f_{2}$, and a detection probability $p$ to maximize social welfare $W$. The sanctions are restricted by a maximum level $F$, i.e., $f_{1}, f_{2} \leq F$, which can be thought of as the offenders' maximum wealth. In addition, we assume that the criminal organization provides extra benefits (or protection) to its members and, at the same time, extracts criminal rents from them. In other words, a member has to pay entry fees $y$ in exchange for the Mafia's extra benefits. ${ }^{3}$

3. The traditional literature, for example Garoupa (2000), specifies that in a monopolistic model potential offenders have to buy a license from the Mafia to be able to commit the offense; that is, the Mafia regulates entry into the criminal market. 
Following Garoupa (2000), the criminal syndicate will choose $y$ to maximize the total revenue, $\Pi$, extracted from its members.

A potential offender engages in a two-stage decision (during stages 2 and 3). Given the policies formed by the government and the Mafia in stage 1 , a potential offender first decides whether to commit a crime (denoted by $C$ ) in the second stage. If he decides to commit a crime, then the offender in turn decides whether to become an organized criminal $(O)$ or an individual criminal $(I)$ in the third stage. An offender obtains $b$ (criminal rent) from committing a crime. The $b$ is private information known only to the offender (and to the criminal organization if he joins the Mafia) and is not revealed to the authorities. In this article, $b$ also reflects the offender's quality in terms of criminal skills, which vary across potential offenders. For simplicity, $b$ is uniformly distributed over $[0,1]$.

A potential offender's net payoff corresponding to the $i$ th choice is denoted by $u_{i}$, where $i=N, O, I$. Thus we have

(1) $u_{N}=0$, if he chooses $N$;

$u_{O}=B-p f_{1}+e-y$, if he chooses $O$;

$u_{I}=b-p f_{2}, \quad$ if he chooses $I$.

The term $B$ is a member's payoff received from participation in organized crime, which comes from the Mafia's payoff shared by all members. The extra benefit $e$ is defined as what a member would obtain by joining a criminal organization, which exceeds what he would obtain when committing the crime alone. As pointed out by Abadinsky (1994), the extra benefit may take the form of greater influence, better business, or better protection. We interpret it concretely as either an increase in income or a reduction in expected sanctions (i.e., the expected sanction of choosing $O$ is $\left[p f_{1}-e\right]$ ) for the Mafia's members. $^{4}$ It will play a prominent role in our analysis.

4. The Mafia may try to recruit individual offenders forcibly through the imposition of violence or harassment. The term $e$ can also be viewed as a benefit from joining the Mafia, stemming from the escape from the Mafia's harassment. When all agents are risk-neutral, such a benefit as joining the Mafia is equivalent to the disutility from refusing to join the Mafia (i.e., engaging in individual crime) in our model.
The member's payoff $B$ crucially depends on the incentive sharing schemes within the criminal organization. In this article we deal with this problem by introducing two different sharing arrangements, namely, uniform and ability-adherent sharing schemes. We begin our analysis with a uniform sharing scheme in the benchmark model and later, in section IV, we will extensively discuss an incentive scheme that adheres to criminals' skills (i.e., in which members receive payoffs based on their performance in the conduct of their criminal activities). In the uniform sharing scheme, the Mafia's payoff is divided equally among its members and, consequently, every member receives an average criminal benefit, that is, $B=\bar{b}$. The average payoff $\bar{b}$ is endogenous and dependent on the members' average criminal skills within the organization.

Ideally, the extra benefit might depend on whether the criminal organization can recruit high-quality members and on how the organization runs its business. However, to focus our point, we shed light on the former effect and abstract the latter effect from the analysis. Thus, it is convincing that the higher the average quality of the Mafia's members is, the greater will be the extra benefits $e$ that the Mafia can create. Therefore, we specify $e=e(\bar{b})=\alpha \bar{b}, 0<\alpha<1$, for convenience, and it also allows us to yield a simpler solution. ${ }^{5}$

\section{THE MODEL}

Following a backward induction, we solve this three-stage game by starting with the criminal choices of a potential offender.

\section{The Potential Offender's Decision}

In the third stage, given that he enters the criminal market, an individual evaluates the benefits and costs of joining the Mafia to decide whether to become an organized criminal. From (1), the "self-selection constraint" reveals that a potential offender will participate

5. In some circumstances, the extra benefit may depend on the size of the criminal organization. Such a specification will yield similar results in the article and merely complicate the model without adding too much insight. A mathematical deduction is available on request. 
FIGURE 2

The Equilibrium Margins in $[N, O, I]$

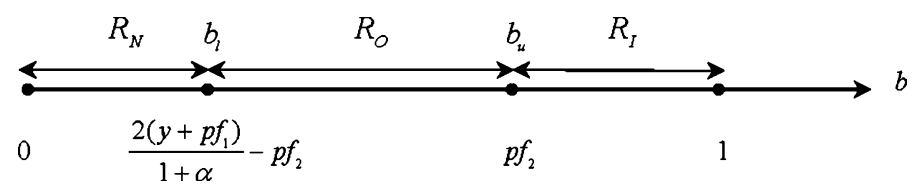

in organized crime as long as $u_{O}>u_{I}$, or equivalently

$$
\begin{aligned}
\bar{b}+e-y-p f_{1} & =\bar{b}(1+\alpha)-y-p f_{1} \\
& >b-p f_{2} .
\end{aligned}
$$

Otherwise, he will be an individual criminal.

In the second stage, potential offenders decide whether to commit an offense. According to (1), the "participation constraints" indicate that committing a crime is worthwhile if $u_{I}>0$ or if $u_{O}>0$, that is, if

$$
\begin{aligned}
& \bar{b}(1+\alpha)-p f_{1}-y>0 \text { or } \\
& \text { if } b-p f_{2}>0 .
\end{aligned}
$$

On the contrary, committing a crime is not worthwhile if

$$
\begin{aligned}
& \bar{b}(1+\alpha)-p f_{1}-y \leq 0 \quad \text { and } \\
& \text { if } b-p f_{2} \leq 0
\end{aligned}
$$

Based on the self-selection constraint in (2) and the participation constraints in (3) and (4), we propose the following proposition.

PROPOSITION 1. Under the uniform sharing scheme, potential offenders with relatively high criminal skills will tend to commit crimes alone, whereas those with relatively low potential criminal rents will choose not to enter the criminal market. The potential offenders who have medium abilities will choose to be organized by the Mafia.

Proof. By a backward induction, we first deal with the offender's decision regarding whether to join the criminal organization, given that he enters the criminal market. Under the uniform sharing arrangement, other things being equal, the self-selection constraint (2) indicates that low-ability offenders (with lower criminal benefits $b$ ) are more likely to join the Mafia and receive more criminal payoffs than they would have received when commit- ting crimes alone. ${ }^{6}$ However, under a uniform sharing scheme, the high-ability offenders tend not to participate in organized crime, because their distinctly high criminal rents will be shared by other free riders with lower criminal rents. Due to the free-rider problem, the offenders with a higher $b$ will choose $I$, rather than $O .^{7}$ Accordingly, as shown in Figure 2, the region $I$ (individual criminals) should be on the right-hand side of $O$ (organized criminals) according to the criminal rent distribution.

We turn to the potential offender's decision regarding whether to commit crimes (i.e., choose $C$ ) or not (i.e., choose $N$ ). In (4) the participation constraint $b \leq p f_{2}$ indicates that potential offenders with very low criminal skills will not commit individual crimes. In addition, the average payoff for Mafia members $\bar{b}$ is dependent on the qualities of the offenders that are organized. Given a government's enforcement $p f_{1}$ and the Mafia's fee $y$, if mostly low-ability offenders join the Mafia, then their participation will result in a very low level of the Mafia's average payoff $\bar{b}$, thus making it more likely that their own net benefit will be negative (i.e., $\bar{b}[1+\alpha] \leq y+p f_{1}$ in equation (4) is true). Thus, it will not be worthwhile for low-ability potential offenders to participate in organized crime, and they will remain as law-abiding citizens. Therefore, Figure 2 indicates that the region $N$ (commits no

6. Once those low-ability offenders choose $O$, the average shared payoff for Mafia members will decrease accordingly. Given that $e>0$, as we will see in next subsection, under certain conditions, some offenders will still be willing to join the Mafia as long as the net profit from joining is positive.

7. If the Mafia provides an unduly large extra benefit to its members (or if the difference $f_{2}-f_{1}$ is positive and extremely large), then offenders with higher criminal rents will also join the criminal organization. However, in such a situation, individual criminals will eventually disappear. To ensure that $O$ and $I$ coexist in equilibrium, we rule out these possibilities in our analysis. In general, as we will see in the next section, given the free-rider problem, $[N, O, I]$ will be a unique equilibrium. 
crime) will be on the left-hand side of $O$ and $I$ within the criminal rent distribution.

Based on these deductions, under a uniform sharing arrangement, people with the lowest criminal rent (or skill) will not commit crime at all $(N)$, people with medium criminal rent will become organized criminals $(O)$, and those who have the highest criminal rent will become individual criminals $(I)$. This constitutes an $[N, O, I]$ equilibrium as described in Figure 2.

Q.E.D.

In what follows we will prove the existence of the $[N, O, I]$ equilibrium, and show that the type $[N, O, I]$ is a unique equilibrium under the Mafia's uniform sharing arrangement.

\section{The Solution of the Equilibrium [N, O, I]}

We denote $R_{O}, R_{I}$, and $R_{N}$ as the proportions of citizens choosing $O, I$, and $N$, respectively, in the community. There are two critical levels of potential criminal rent, namely, $b_{l}$ and $b_{u}$ (where $b_{l} \leq b_{u}$ ), that determine whether an individual will commit crime and the way he commits the crime. According to Proposition 1, citizens with criminal rents $0 \leq b \leq b_{l}$ will not enter the criminal market at all. For those who decide to enter the criminal market, offenders with criminal rents $b_{l}<b \leq b_{u}$ will join a criminal organization, and those who have a relatively higher criminal ability $b_{u}<b \leq 1$ will decide to commit crime alone. Thus, we can define the average payoff of a criminal organization $\bar{b}$, and the equilibrium proportions $R_{N}, R_{O}$, and $R_{I}$ as follows:

$$
\bar{b}=\int_{b_{l}}^{b_{u}} b d b / \int_{b_{l}}^{b_{u}} d b=\left(b_{l}+b_{u}\right) / 2
$$

$$
\begin{aligned}
& R_{N}=\int_{0}^{b_{l}} d b=b_{l}, \\
& R_{O}=\int_{b_{l}}^{b_{u}} d b=b_{u}-b_{l}, \\
& R_{I}=\int_{b_{u}}^{1} d b=1-b_{u} .
\end{aligned}
$$

The marginal potential offender who has criminal rent $b_{l}$ is indifferent in terms of choosing between joining a criminal organization and committing no crime. Thus, from the participation constraints and (5), we have:

$$
0=(1+\alpha)\left(b_{l}+b_{u}\right) / 2-y-p f_{1} .
$$

By analogy, the potential offenders who have a criminal rent $b_{u}$ are indifferent in terms of choosing between $I$ and $O$. That is,

$$
(1+\alpha)\left(b_{l}+b_{u}\right) / 2-y-p f_{1}=b_{u}-p f_{2} .
$$

We now define the regions of $N, O$, and $I$ as $\Omega_{N}, \Omega_{O}$, and $\Omega_{I}$, respectively. Thus, we establish Proposition 2 to describe the equilibrium $[N, O, I]$ as follows.

PROPOSITION 2. Under the [N, O, I] equilibrium, the criminal ability distribution of three types of agents $\mathrm{N}, \mathrm{O}$, and $\mathrm{I}$, are, respectively:

$$
\begin{aligned}
\Omega_{N} & \equiv\left[0,2\left(y+p f_{1}\right) /(1+\alpha)-p f_{2}\right] ; \\
\Omega_{O} & \equiv\left(2\left[y+p f_{1}\right] /(1+\alpha)-p f_{2}, p f_{2}\right] ; \\
\Omega_{I} & \equiv\left(p f_{2}, 1\right] .
\end{aligned}
$$

Proof. From (9) and (10), the equilibrium critical values $b_{l}$ and $b_{u}$, respectively, are given by:

$$
\begin{aligned}
& b_{l}=2\left(y+p f_{1}\right) /(1+\alpha)-p f_{2} \text { and } \\
& b_{u}=p f_{2} .
\end{aligned}
$$

According to (11), we immediately have the equilibrium regions of $N, O$, and $I$. Q.E.D.

From (11), we also learn that the existence of the equilibrium $[N, O, I]$ should satisfy the condition $0<b_{l}<b_{u}<1$, that is, $(1+\alpha) p f_{2} /$ $2-p f_{1}<y<(1+\alpha) p f_{2}-p f_{1}$ and $p f_{2}<1$. When critical rents $b_{l}$ and $b_{u}$ are determined, the average criminal rent can also be solved from (5) and is given by $\bar{b}=\left(p f_{1}+y\right) /$ $(1+\alpha)$.

We can be assured of the existence of this equilibrium. Proposition 2 indicates that the offenders with criminal rents $b \in \Omega_{O}$ will join a criminal organization. Let the lower bound of $\Omega_{O}$ be $2\left(y+p f_{1}\right) /(1+\alpha)-p f_{2}+\varepsilon$, where $\varepsilon$ represents an infinitesimal positive value, that is, $\varepsilon \rightarrow 0^{+}$. Accordingly, the average criminal rent $\bar{b}$ is $\left(p f_{1}+y\right) /(1+\alpha)+\varepsilon / 2$. Substituting this into (1), the payoff for potential offenders choosing $O, u_{O}=(1+\alpha) \varepsilon / 2>0$, which satisfies the participation constraint. If an offender with an upper-boundary criminal rent $p f_{2}$ chooses $I$, then his payoff is $b-p f_{2}=p f_{2}-p f_{2}=0$, which 
is less than $(1+\alpha) \varepsilon / 2$. This implies that he must be a Mafia member.

Similarly, it follows from Proposition 2 that the offenders with $b \in \Omega_{I}$ choose to commit crimes alone. By letting the lower bound of $\Omega_{1}$ be $p f_{2}+\varepsilon$, from (1), an offender with $b=p f_{2}+\varepsilon$, will obtain a benefit $u_{I}=b-$ $p f_{2}=\varepsilon$ if he chooses $I$, and he will receive a benefit $(1+\alpha) \varepsilon / 2$ if he chooses $O$. Because $0<\alpha<$ 1 , we have $\varepsilon>(1+\alpha) \varepsilon / 2$, implying that this offender will rationally choose $I$. Therefore, we verify the existence of the equilibrium $[N, O, I]$ and ensure its credibility. ${ }^{8}$

\section{The Optimal Law Enforcement and the Equilibrium Crime Rate}

Given that the government and the Mafia play a Cournot-Nash game, this subsection will analyze these two parties' behaviors and in turn determine the Mafia's optimal extraction, the government's optimal law enforcement, and the equilibrium crime rate.

Mafia. In our model the criminal organization is structured as a pure franchise that provides benefits $B=e=(1+\alpha) \bar{b}$ and receives an entry fee $y$. The way the criminal organization runs the business on the basis of the extra benefit, such as by giving bribes to officials, is abstracted from the model. In particular, we do not analyze how the criminal organization pays these amounts to arrive at an optimal level of the extra benefit $\alpha$. For the sake of comparison with the existing literature, we treat $\alpha$ as a parameter. Though simple, such a specification allows us to capture a number of scenarios and focus attention on the relationship between theindividual's rationalchoice, the marketstructure for crime, and the optimal enforcement.

Given the government's enforcement policy, the Mafia's optimization problem is to maximize its total profit, that is,

$$
\begin{aligned}
\max _{y} \Pi & =\int_{b_{l}}^{b_{u}} y d b-Z \\
& =y\left(b_{u}-b_{l}\right)-Z,
\end{aligned}
$$

8. The analysis can be easily reduced to two possible special cases. First, following Figure 2, the equilibrium $[N, I]$ exists if $b_{l} \geq b_{u}>0$ and $b_{u}<1$, implying that the conditions $y \geq(1+\alpha) p f_{2}-p f_{1}$ and $p f_{2}<1$ must be satisfied. Second, if $0<b_{l}<b_{u}$ and $b_{u} \geq 1$, the equilibrium $[N, O]$ will emerge. The corresponding conditions of existence are $(1+\alpha) / 2-p f_{1}<y<(1+\alpha)-p f_{1}$ and $p f_{2} \geq 1$. where $Z$ is the Mafia's fixed operation cost. ${ }^{9}$ By substituting equilibrium values $b_{l}$ and $b_{u}$ from (11) into (12), we obtain the firstorder condition $\partial \Pi / \partial \mathrm{y}=2\left[p f_{2}-\left(2 y+p f_{1}\right) /\right.$ $(1+\alpha)]=0$, which yields the Mafia's optimal extraction:

$$
y^{R F}=\left[(1+\alpha) p f_{2}-p f_{1}\right] / 2 .
$$

Equation (13) conveys very intuitive results whereby the Mafia's optimal extraction $y^{R F}$ increases with the extra benefit $\alpha$ and decreases with the expected sanction of organized crime $p f_{1}$. By contrast, when the expected sanction of the alternative choice $I, p f_{2}$, increases, the Mafia will be able to extract more rent from its members.

Government. Let us denote $h_{1}$ and $h_{2}$ as the average harm to a society resulting from an organized and an individual criminal offense, respectively. It is plausible to specify $h_{1} \geq$ $h_{2}>0$. It is also important to take into account the attendant externality generated by the Mafia. For this, we assume that producing the extra benefit $e$ will generate a negative externality $\beta e$ to a society, where $\beta$ reflects the degree of such an externality. Accordingly, the aggregate surplus stemming from $O$ can be described by $\int_{b_{l}}^{b_{u}}\left(\bar{b}+\alpha e-h_{1}-\beta e\right) d b$. For analytical convenience, we further define $\theta \equiv \beta-\alpha$ (and $0<\theta<1$ ), which measures the degree of the net externality of producing $e$.

Furthermore, it is evident that the surplus stemming from $I$ is $\int_{b_{u}}^{1}\left(b-h_{2}\right) d b$. To add these two surpluses, the social welfare $W$ is given by: $\int_{b_{l}}^{b_{u}}\left(b-h_{1}-\theta e\right) d b+\int_{b_{u}}^{1}\left(b-h_{2}\right) d b-C(p)$. The term $C$ stands for the cost of detection and conviction, which is an increasing function of $p$, that is, $\partial C / \partial p>0$. For simplicity, we assume $C(p)=c p$ with $c>0$ in the analysis that follows.

Given the Mafia's extraction $y$, the authorities choose the optimal enforcement $p, f_{1}$, and $f_{2}$ so as to maximize the social welfare $W$, that is,

9. If $Z$ is related to the extra benefit and takes the form $Z=z \cdot e$ with $z>0$, our main results are not altered. 


$$
\begin{aligned}
\max _{p, f_{1}, f_{2}} W= & \int_{b_{l}}^{b_{u}}\left(\bar{b}-h_{1}-\theta e\right) d b \\
& +\int_{b_{u}}^{1}\left(b-h_{2}\right) d b-C(p) \\
= & {\left[1-(1-\alpha \theta) b_{l}^{2}\right.} \\
& \left.-\alpha \theta b_{u}^{2}\right] / 2-\left(b_{u}-b_{l}\right) h_{1} \\
& -\left(1-b_{u}\right) h_{2}-C(p) .
\end{aligned}
$$

We recall that in the analysis we should confine the sanctions to the limitation $f_{1}, f_{2}, \leq F$, due to the problem of limited liability. In addition, we further assume that $f_{2}=f$ and $f_{1}=f+\Delta f$, where $\Delta f \geq 0$, reflecting the fact that an organized criminal may incur higher penalties than an individual criminal. With this assumption, (11) becomes

$$
\begin{aligned}
b_{l}= & {[2 y+(1-\alpha) p f+2 p \cdot \Delta f] } \\
& /(1+\alpha) \text { and } \\
b_{u}= & p f
\end{aligned}
$$

and, accordingly, the resulting equations yield the following comparative statics:

$$
\begin{aligned}
\partial b_{l} / \partial p & =[(1+\alpha) f+2 \Delta f] /(1+\alpha), \\
\partial b_{l} / \partial f & =(1-\alpha) p(1+\alpha), \\
\partial b_{l} / \partial \Delta f & =2 p /(1+\alpha), \\
\partial b_{u} / \partial p & =f \\
\partial b_{u} / \partial f & =p, \quad \text { and } \\
\partial b_{u} / \partial \Delta f & =0 .
\end{aligned}
$$

Differentiating $W$ with respect to $p, f$, and $\Delta f$, we have

$$
\begin{aligned}
\partial W / \partial p= & {\left[h_{1}-(1-\alpha \theta) b_{l}\right][(1-\alpha) f} \\
& +2 \Delta f] /(1+\alpha) \\
& -\left[\alpha \theta b_{u}+\left(h_{1}-h_{2}\right)\right] f-c
\end{aligned}
$$

$$
\begin{aligned}
\partial W / \partial f= & p\left\{(1-\alpha)\left[h_{1}-(1-\alpha \theta) b_{l}\right]\right. \\
& /(1+\alpha)-\left[\alpha \theta b_{u}\right. \\
& \left.\left.+\left(h_{1}-h_{2}\right)\right]\right\}
\end{aligned}
$$

$$
\begin{aligned}
\partial W / \partial \Delta f= & 2 p\left[h_{1}-(1-\alpha \theta) b_{l}\right] \\
& /(1+\alpha) .
\end{aligned}
$$

Due to $(1-\alpha) f+2 \Delta f>0$, we should specify $h_{1}-(1-\alpha \theta) b_{l}>0$ in (15a) to guarantee an interior solution for $p$ (i.e., $\partial W / \partial p=0$ ). Given that, from $(15 \mathrm{c})$ we have $\partial W / \partial \Delta f>0$, implying that the government would like to impose a higher penalty on organized criminals than individual criminals. That is, as a best policy, the government will set $\Delta f$ as the maximal level, that is, $\Delta f \equiv f_{1}-f_{2}=F-f$. By substituting $\Delta f=F-f$ into (15a) and letting the resulting equation be 0 (i.e., $\partial W / \partial p=0$ ), the optimal $p$ satisfies:

$$
\begin{aligned}
h_{1}- & (1-\alpha \theta) b_{l} \\
= & (1+\alpha)\left[c+\left(\alpha \theta b_{u}+h_{1}-h_{2}\right) f\right] \\
& /[2 F-(1+\alpha) f] .
\end{aligned}
$$

Putting (15b) and (15d) together thus immediately yields

$$
\begin{aligned}
\partial W / \partial f= & p[-2(F-f) \\
& \left.\cdot\left(\alpha \theta b_{u}+h_{1}-h_{2}\right)+(1-\alpha) c\right] \\
& /[2 F-(1+\alpha) f]
\end{aligned}
$$

In (16), if $f=F$, then $\partial W / \partial f>0$ is true. In addition, from $(15 \mathrm{~b})$ we also have $\partial^{2} W / \partial f^{2}=$ $-p \cdot\left[(1-\alpha)(1-\alpha \theta) /(1+\alpha) \cdot\left(\partial b_{l} / \partial f\right)+\right.$ $\left.\alpha \theta \cdot\left(\partial b_{u} / \partial f\right)\right]<0$, meaning that the $W$ function is concave in $f$. With this understanding, the optimal $f$ will be bound at $F$ and hence $\Delta f=F-F=0$. In other words, the government's best policy is to set the highest sanction, that is, $f_{1}^{R F}=f_{2}^{R F}=F$. Given $f_{1}^{R F}=f_{2}^{R F}=F$, from $\left(11^{\prime}\right)$ and (15a), the government's optimal law enforcement is given by

$$
\begin{aligned}
(p f)^{R F}= & (1+\alpha)\left[-2 \alpha h_{1}+(1+\alpha) h_{2}\right. \\
& -2(1-\alpha \theta)(1-\alpha) y \\
& /(1+\alpha)-(1+\alpha) c / F] \\
& /\left(4 \alpha^{2} \theta+\alpha^{2}-2 \alpha+1\right) .
\end{aligned}
$$

Equation (17) indicates that the optimal law enforcement is negatively related to the level of the Mafia's entry fee $y$. In the $[N, O, I]$ equilibrium, a higher entry fee discourages the potential offenders from committing any crime, and thus the government can save on the law enforcement budget given a tolerable crime rate. That is to say, the government can regard the Mafia's entry fee as a substitute for law enforcement in maximizing social welfare. 
The two reaction functions (13) and (17) determine the equilibrium law enforcement and the Mafia's extraction simultaneously:

$$
\begin{aligned}
p^{*} f^{*}= & (1+\alpha)\left[-2 \alpha h_{1}\right. \\
& \left.+(1+\alpha) h_{2}-(1+\alpha) c / F\right] \\
& /\left(\alpha^{3} \theta+3 \alpha^{2} \theta-\alpha+1\right), \\
y^{*}= & \alpha p^{*} f^{*} / 2 \\
= & \alpha(1+\alpha)\left[-2 \alpha h_{1}\right. \\
& \left.+(1+\alpha) h_{2}-(1+\alpha) c / F\right] \\
& / 2\left(\alpha^{3} \theta+3 \alpha^{2} \theta-\alpha+1\right) .
\end{aligned}
$$

Substituting (18) into (11) yields the equilibrium critical values $b_{l}$ and $b_{u}$ as follows:

$$
b_{u}^{*}=p^{*} f^{*} \quad \text { and } \quad b_{l}^{*}=p^{*} f^{*} /(1+\alpha)
$$

PROPOSITION 3. Under the uniform sharing scheme, $(i)$ if the Mafia cannot provide any extra benefit to its members $(\alpha=e=0)$, the criminal market turns out to be perfectly competitive and all offenders are individual criminals; (ii) if $p^{*} f^{*} \rightarrow 1$, the criminal market will be characterized by monopoly.

Proof. It follows from (19) that if $\alpha=e=0$, in equilibrium the critical value $b_{l}$ will atrophy to $b_{u}$. By referring to Figure 2, this implies that no one will choose $O$ and all offenders will commit individual crimes. Thus, the criminal market becomes perfectly competitive. By contrast, when $p^{*} f^{*} \rightarrow 1$, from (11) we learn that the critical values reduce to $b_{u}^{*} \rightarrow 1$ and $b_{l}^{*} \rightarrow 1 /(1+\alpha)$. These indicate that $R_{I}$ shrinks to zero and $R_{O}=b_{u}^{*}-b_{l}^{*}=$ $\alpha /(1+\alpha)$.

Q.E.D.

The economic intuition behind the result of Proposition 3 is straightforward. As $\alpha=e=0$, relative to $I$, the only benefit of $O$ is in the shared average payoff $\bar{b}$. However, any offender with a relatively higher ability will choose $I$ to avoid sharing his distinctly higher criminal rent with those who have lower rents. The free-rider problem thus chokes off any incentive for joining the Mafia. By contrast, if the government raises its law enforcement to a very high level, that is, $p^{*} f^{*} \rightarrow 1$ (or even larger than 1), the high intensity of law enforcement will eliminate all possibility of indi- vidual crimes. ${ }^{10}$ However, because the Mafia's extra benefit could take the form of a reduction in terms of the government's detection, all offenders will in such circumstances choose $O$ and take shelter in the Mafia. The criminal market will therefore be characterized by monopoly. ${ }^{11}$

The Equilibrium Crime Rate. Let us define the equilibrium crime rate as $R \equiv R_{O}+R_{I}$. By referring to Figure 2, the equilibrium crime rate is

$$
\begin{aligned}
R= & 1-b_{l}^{*}=1-\left[-2 \alpha h_{1}\right. \\
& \left.+(1+\alpha) h_{2}-(1+\alpha) c / F\right] \\
& /\left(\alpha^{3} \theta+3 \alpha^{2} \theta-\alpha+1\right) .
\end{aligned}
$$

According to (19) and (20), we then have the following.

PROPOSITION 4. If the Mafia creates a larger extra benefit for its members, the equilibrium crime rate will rise in response. However, a higher Mafia extra benefit may not always be helpful in recruiting more members and increasing the size of the criminal organization after all.

\section{Proof. See Appendix A.}

From (20), the result $\partial R / \partial \alpha=-\left(\partial b_{l}^{*} / \partial \alpha\right)>0$ indicates that a rise in the Mafia's extra benefit will cause some citizens who initially abide by the law to join the Mafia and, as a consequence, the overall crime rate will rise.

This, however, does not imply that the number of the Mafia's members $R_{O}=$ $b_{u}^{*}-b_{l}^{*}$ (see [7]) will also be increased by $\alpha$. Intuitively speaking, on the one hand, $\partial b_{l}^{*} / \partial \alpha<0$ reveals that following a rise in $\alpha$, some potential offenders with relatively low $b$ will be enticed to join the Mafia. However, on the other hand, by referring to (11) and (19), the result $\partial b_{u}^{*} / \partial \alpha=\partial\left(p^{*} f^{*}\right) / \partial \alpha \gtreqless 0$

10. Generally speaking, $p f$ would be larger than 1 (the upper bound of criminal benefit) only when the social harm resulting from an offense is very large. If $p f$ were large enough, then all criminal behavior would be eliminated.

11. Under such a case when the Mafia provides more extra benefits to its members (a larger $\alpha$ ), then the size of the monopolistic criminal organization will grow. 
indicates that a higher $\alpha$ will have a mixed effect in terms of attracting high-ability offenders. A higher $\alpha$ may also generate an incentive effect in terms of attracting high-ability offenders to the criminal organization. Nevertheless, when the Mafia provides more benefits to its members, at the same time, it will also extract more from them (inferred from [11]). Because the government regards the Mafia's entry fee as a substitute for law enforcement, the optimal law enforcement will decrease (inferred from [17]). This will encourage offenders to choose $I$ rather than $O$. Due to this negative effect, a higher Mafia extra benefit may not always help in terms of recruiting more offenders and increasing the size of the criminal organization. This result potentially contributes to an interesting implication whereby the size of the Mafia is ambiguously related to the crime rate.

Propositions 3 and 4 also contribute an important implication to the existing literature. For ease of comparison with the existing literature, we assume that (1) an individual criminal does the same harm to society as an organized criminal, that is, $h_{1}=h_{2}=h$; and (2) the extra benefit $e$ is a pure "social transfer" and hence $\theta=$ 0 (i.e., $\alpha=\beta$ ) (for example, an increase in the extra benefit via a reduction in the government's deterrence would mean an increase in social harm). Given those assumptions, if the Mafia's extra benefit is absent $(\alpha=0)$, the equilibrium crime rate (20) and law enforcement (19) are reduced to those of Garoupa (2000). As such, as argued by Garoupa (2000), the existence of the Mafia will thus become welfare-improving to society as a whole. However, it follows from (19) and (20) that when $\alpha>0$, because all offenders can choose the criminal patterns that best suit them under the self-selection mechanism, the society will have a higher crime rate under self-selection market than under monopoly. Moreover, a monopolistic crime market does not necessarily result in a reduction of the optimal law enforcement. As a result, Propositions 3 and 4 sharply contradict the traditional viewpoints of Buchanan (1973) and Garoupa (2000). ${ }^{12}$

12. See Chang et al. (2002) (an earlier version of this article) for a more complete discussion.

\section{DISCUSSIONS AND EXTENSIONS}

The benchmark framework is well worth extending to tackle related issues. In this section we consider two extensions.

\section{An Ability-Adherent Sharing Scheme}

In section III it is found that, under a uniform sharing scheme, $[N, O, I]$ is the unique equilibrium in the self-selection criminal market. This equilibrium indicates that only relatively lowability criminals join a criminal organization, whereas high-ability criminals commit crimes alone. Perhaps this gives us the impression that a criminal organization might merely be formed by low-end criminals or by "a group of street gangsters." However, this equilibrium does not seem to properly capture the typical profiles of criminal organizations that we see in real life, mostly because we assume the existence of a uniform sharing scheme. In this subsection we consider another sharing scheme that adheres to members' abilities and, accordingly, demonstrates the existence of a distinctive equilibrium, namely, the $[N, I, O]$ equilibrium. This $[N, I, O]$ equilibrium may fit into some of the familiar profiles we often read about in the literature regarding criminal organizations. One point should be noted here. Although our central concern is to verify the existence of the $[N, I, O]$ equilibrium, we do not, however, intend to exclude the possibility of the existence of other equilibrium, such as $[N, O, I]$, in the ability-adherent sharing scheme. ${ }^{13}$

In the ability-adherent sharing scheme, the Mafia's payoff is distributed according to members' abilities. We denote $R(b)$ as a sharing function, with the payoff positively relating to members' personal criminal rents within the Mafia. Thus, we can specify a member's payoff as $R(b) \bar{b}(1+\alpha)-y-p f_{1}$, where $\int_{b \in \Omega_{O}} R(b) d b=\int_{b \in \Omega_{O}} d b$ and $R^{\prime}(b)>0 .{ }^{14}$

13. In fact, some characteristics of the $[N, O, I]$ equilibrium under an ability-adherent sharing scheme are similar to those in the uniform sharing case. See the working paper of Chang et al. (2002) for the details.

14. To make a meaningful comparison with a "uniform" sharing scheme, we use the average benefit $\bar{b}$, rather than the total benefit $\int_{b \in \Omega_{o}} b d b$ to describe a member's distributed benefit. When $R(b)=1 \forall b$, the abilityadherent sharing arrangement is reduced to the uniform-sharing one. We first denote $S(b)$ as the "actual" sharing proportion out of the Mafia's total payoff, and then $\int_{b \in \Omega_{0}} S(b) d b=1$. By so doing, we obtain $S(b)$ $\int_{b \in \Omega_{o}} b d b=R(b) \cdot \bar{b}$, where $R(b) \equiv S(b) \cdot \int_{b \in \Omega_{o}} d b$ and $\bar{b} \equiv \int_{b \in \Omega_{o}} b d b / \int_{b \in \Omega_{o}} d b$. That is, $\int_{b \in \Omega_{O}} R(b) d b \equiv \int_{b \in \Omega_{o}} d b$. 
Assume that there are two critical values $b_{l}$ and $b_{u}$ (where $b_{l}<b_{u}$ ) such that

$$
\begin{aligned}
& b \in\left[0, b_{l}\right] \Rightarrow \text { no crime; } \\
& b \in\left(b_{l}, b_{u}\right] \Rightarrow \text { individual crime; } \\
& b \in\left(b_{u}, 1\right] \Rightarrow \text { organized crime }
\end{aligned}
$$

Given (21), the average benefit to the Mafia's members is $\bar{b}=\left(1+b_{u}\right) / 2$. Accordingly, we can find the critical values $b_{l}$ and $b_{u}$, which satisfy both the self-selection and participation constraints as follows:

$$
\begin{gathered}
(1+\alpha) R\left(b_{u}\right)\left(1+b_{u}\right) / 2-y-p f_{1} \\
=b_{u}-p f_{2}, \\
b_{l}-p f_{2}=0 .
\end{gathered}
$$

Equation (22a) can be further rewritten as:

$$
\Phi\left(b_{u} ; \alpha\right)=y+p \cdot \Delta f,
$$

where $\Phi\left(b_{u} ; \alpha\right) \equiv(1+\alpha) R\left(b_{u}\right)\left(1+b_{u}\right) / 2-b_{u}$. Equation (23) indicates that, compared with $I$, the relative benefit of choosing $O$ is $\Phi(b ; \alpha)$ and its relative cost is $y+p \cdot \Delta f$.

Based on (21)-(23), we have the following proposition,

PROPOSITION 5. Under the ability-adherent sharing arrangement, if the self-selection constraint $\Phi(b ; \alpha)>0 \forall b \in\left(b_{u}, 1\right]$ and $\partial \Phi /$ $\left.\partial b\right|_{b=b_{u}}>0$, then the equilibrium [N, I, O] exists.

\section{Proof. See Appendix B.}

Proposition 5 points out that the $[N, I, O]$ equilibrium exists as long as the following conditions hold. First, for potential offenders with $b>b_{u}$, the relative benefit of joining a criminal organization compared to committing crime alone is positive (i.e., $\Phi(b ; \alpha)>0$, $\left.\forall b \in\left(b_{u}, 1\right]\right)$. To satisfy this, the Mafia must provide a sufficiently large extra benefit to its members. Second, the sharing scheme is designed such that the relative benefit from joining a criminal organization increases with an offender's criminal ability (i.e., $\partial \Phi /\left.\partial b\right|_{b=b_{u}}>0$ ).

A simple example is useful to verify the existence of the equilibrium $[N, I, O]$. Let us denote $S(b)$ as a member's "actual" sharing proportion out of the Mafia's total crimi- nal payoff and assume that $S(b)=b^{2} /$ $\left[\int_{b \in \Omega_{Q}} b^{2} d b\right]=3 b^{2} /\left(1-b_{u}^{3}\right)$. Accordingly, we can further calculate the sharing functions $R(b)=S(b) \int_{b \in \Omega_{0}} d b=3 b^{2} /\left[1+b_{u}+b_{u}^{2}\right]$ and $\int_{b \in \Omega_{o}} R(b) d b \stackrel{b \in \Omega_{0}}{=}-b_{u}$. From (23) with this sharing function, we can obtain

$$
\begin{aligned}
\Phi\left(b_{u} ; \alpha\right)= & -b_{u} \\
+ & 3(1+\alpha) b_{u}^{2}\left(1+b_{u}\right) \\
/ & {\left[2\left(1+b_{u}+b_{u}^{2}\right)\right]>0 } \\
\text { if } \alpha>\left[2-b_{u}\left(1+b_{u}\right)\right] & \\
/( & \left.3 b_{u}\left(1+b_{u}\right)\right], \\
\partial \Phi /\left.\partial b\right|_{b=b_{u}}= & {\left[-1+(1+3 \alpha) b_{u}\right.} \\
& +3(1+2 \alpha) b_{u}^{2} \\
& +(1+3 \alpha) b_{u}^{3} \\
& \left.+(1+3 \alpha) b_{u}^{4} / 2\right] \\
& /\left[\left(1+b_{u}+b_{u}^{2}\right)^{2}\right]>0 .
\end{aligned}
$$

Equations (24) and (25) satisfy the requirements stated in Proposition 5 and verify the existence of the equilibrium $[N, I, O]$.

\section{Law Enforcement Distortion of the Mafia}

In this extension we consider a situation where the Mafia is able to command some influence in weakening criminal deterrence. One way of seeing this is that the influence on law enforcement is exerted through the corruption of the law enforcers or police officers. ${ }^{15}$ To model this distortion of the Mafia, we simply specify that the extra benefit $e$ provided by the Mafia increases with $p f_{1}$ and takes the following form:

$$
e=\alpha \cdot \bar{b}+\tau p f_{1}, \quad \text { with } 0<\tau<1 .
$$

According to (26), the payoff of an organized criminal changes to:

$$
\begin{aligned}
u_{O} & =\bar{b}-p f_{1}+e-y \\
& =\bar{b}-(1-\tau) p f_{1}+\alpha \cdot \bar{b}-y .
\end{aligned}
$$

We learn from (27) that the effective law enforcement $(1-\tau) p f_{1}$ could be reduced by the Mafia and $\tau$ measures the degree of such an enforcement distortion. Note that, under this specification, $\alpha \cdot \bar{b}$ will only be viewed as extra income from joining the Mafia.

15. We are grateful to an anonymous referee for bringing this point to our attention. 
Because the modification of the extra benefit $e$ does not alter the equilibrium characteristic of $[N, O, I]$, according to (27), the critical values of the lower and upper bounds in $\left(11^{\prime}\right)$ can be changed to:

$$
\begin{aligned}
b_{l}= & {[2 y+(1-\alpha-2 \tau) p f} \\
& +2(1-\tau) p \cdot \Delta f] /(1+\alpha) \quad \text { and } \\
b_{u}= & p f .
\end{aligned}
$$

The government, subject to $0<f_{1}, f_{2} \leq F$, chooses $p, f$, and $\Delta f$ to maximize the social welfare $W$ reported in (15). Solving this optimization problem yields the following first-order conditions

$$
\begin{aligned}
\partial W / \partial p= & {\left[h_{1}-(1-\alpha \theta) b_{l}\right] } \\
& \cdot[(1-\alpha-2 \tau) f+2 \Delta f] \\
& /(1+\alpha)-\left[\alpha \theta b_{u}\right. \\
& \left.+\left(h_{1}-h_{2}\right)\right] f-c
\end{aligned}
$$

$$
\begin{aligned}
\partial W / \partial f= & p\{(1-\alpha-2 \tau) \\
& \cdot\left[h_{1}-(1-\alpha \theta) b_{l}\right] /(1+\alpha) \\
& \left.-\left[\alpha \theta b_{u}+\left(h_{1}-h_{2}\right)\right]\right\}
\end{aligned}
$$

$$
\begin{aligned}
\partial W / \partial \Delta f= & 2(1-\tau) p\left[h_{1}\right. \\
& \left.-(1-\alpha \theta) b_{l}\right] /(1+\alpha) .
\end{aligned}
$$

To obtain an interior solution for $p$ (i.e., $\partial W /$ $\partial p=0)$, we should assume $\left[h_{1}-(1-\alpha \theta) b_{l}\right]$. $[(1-\alpha-2 \tau) f+2 \Delta f]>0$. In the relevant studies, there is a common assumption whereby the social harm stemming from a crime exceeds the criminal rent, that is, $h_{1}-(1-\alpha \theta) b_{l}>0$ in our model.

Following a similar approach to that in the last section, from (28a)-(28c) we can easily obtain the optimal sanctions $f_{1}^{R F}=f_{2}^{R F}=F$, and, as a consequence, the government's optimal law enforcement is given by

$$
\begin{aligned}
(p f)^{R F}= & (1+\alpha)\left[-2(\alpha+\tau) h_{1}\right. \\
& +(1+\alpha) h_{2}-2(1-\alpha \theta) \\
& \cdot(1-\alpha-2 \tau) y /(1+\alpha) \\
& -(1+\alpha) c / F] \\
& /\left[(1-\alpha-2 \tau)^{2}(1-\alpha \theta)\right. \\
& \left.+(1+\alpha)^{2} \alpha \theta\right] .
\end{aligned}
$$

From (29), we immediately have

$$
\partial(p f)^{R F} / \partial \tau \gtreqless 0,
$$

implying that, in the presence of the enforcement distortion $\tau$, increasing the severity of law enforcement is no longer an effective policy in the reduction of crimes and in the improvement of social welfare. As the enforcement distortion $\tau$ increases, some individuals who choose $N$ initially will be allured to be organized by the Mafia (i.e., it follows from equation (11") that $b_{l}$ falls as $\tau$ increases) and, consequently, organized crime will increase. To deter organized crime and reduce the social harm arising there from, the authorities at first would like to increase the law enforcement $p f$. The stronger law enforcement is, however, the greater will be the enforcement distortion generated by the Mafia. To constrain the law enforcement distortion, the government then may decrease $p f$. Because the law enforcement is congested, the government will be in a dilemma in terms of deterring crime and maximizing social welfare. This result is akin to that in Chang et al. (2000), who incorporate police corruption and the social-norm mechanism into the Becker (1968) model and use it to address the dilemma of law enforcement facing a government.

The Mafia's optimization problem is similar to that of (12). Nevertheless, to incorporate the corruption cost into the Mafia's objective function, we modify the specification of operating costs as $Z=Z_{0}+Z_{1} \cdot \tau p f_{1}$, where $Z_{0}$ and $Z_{1}$ are constant and positive. Given that, by solving the Mafia's optimization problem, we obtain the optimal extraction as

$$
y^{R F}=\left[(1+\alpha) p f_{2}-(1-\tau) p f_{1}\right] / 2 .
$$

This indicates that a higher $\tau$ will allow the Mafia to extract more rent from its members.

Two reaction functions in $\left(13^{\prime}\right)$ and (29) determine the equilibrium law enforcement and the Mafia's extraction simultaneously:

$$
\begin{aligned}
p^{*} f^{*}= & (1+\alpha)\left[-2(\alpha+\tau) h_{1}\right. \\
& \left.+(1+\alpha) h_{2}-(1+\alpha) c / F\right] \\
& /[(1-\alpha \theta)(1-\alpha-2 \tau)(1-\tau) \\
& \left.+(1+\alpha)^{2} \alpha \theta\right], \\
y^{*}= & (\alpha+\tau) p^{*} f^{*} / 2 .
\end{aligned}
$$


Moreover, substituting (30) into (11") yields the equilibrium critical values:

$$
\begin{aligned}
b_{l}^{*} & =(1-\tau) p^{*} f^{*} /(1+\alpha) \quad \text { and } \\
b_{u}^{*} & =p^{*} f^{*} .
\end{aligned}
$$

These results allow us to establish Proposition 6 as follows.

PROPOSITION 6. In the presence of the enforcement distortion of the Mafia, under the (sufficient) condition, $\tau>1-$ $\sqrt{(1+\alpha)^{2} \alpha \theta /[2(1-\alpha \theta)]}$ an increase in the enforcement distortion $\tau$ will result in a higher rate of crime in the society as a whole.

Proof. From (30) and (31), it is easy to derive:

$$
\begin{aligned}
\partial R / \partial \tau= & \left\{\left[1+(1-\tau) \Gamma_{\tau} / \Gamma\right]\right. \\
& \cdot\left[-2(\alpha+\tau) h_{1}\right. \\
& \left.+(1+\alpha) h_{2}-(1+\alpha) c / F\right] \\
& \left.+2(1-\tau) h_{1}\right\} / \Gamma
\end{aligned}
$$

where $\Gamma \equiv(1-\alpha \theta)(1-\alpha-2 \tau)(1-\tau)+(1+$ $\alpha)^{2} \alpha \theta>0$ and $\Gamma_{\tau} \equiv \partial \Gamma / \partial \tau=(1-\alpha \theta)(-3+$ $\alpha+4 \tau)$. Given the (sufficient) condition $\tau>1-\sqrt{(1+\alpha)^{2} \alpha \theta /[2(1-\alpha \theta)]}, \Gamma+(1-$ $\tau) \Gamma_{\tau}>0$ is true, and, as a result, $\partial R / \partial \tau>0$.

Q.E.D.

In (32) there are three strengths in governing the impact of a rise in $\tau$ on the aggregate crime rate. First, as $\tau$ rises, given a particular entry fee $y$, some individuals who choose $N$ initially will be allured to choose $O$. Under this situation, the government may resort to stronger law enforcement to deter the growth of organized crime. This will give rise to a deterrence effect in terms of decreasing the crime rate. However, the later second and third effects refer to opposing impacts on the crime rate. The second effect is that as already emphasized, in the presence of $\tau$ the discipline effect of the government's enforcement is plagued by the distortion of the Mafia. To constrain the enforcement distortion, the government should let $p f$ decrease. Crimes thus may grow, accordingly. Third, we learn from $\left(14^{\prime}\right)$ that the Mafia will extract more rents from its members because the Mafia can provide better protection against the criminal penalty imposed on organized criminals. Given that the government's enforcement and the Mafia's entry fee are substitutes, in response to a higher $y$, the government will decrease law enforcement $p f$ and tolerate more crimes. Clearly, if the last two effects sufficiently outweigh the first effect, the equilibrium crime rate rises in response to a higher degree of enforcement distortion $\tau$. The sufficient condition indicates that intuitively, the outcome is more likely to become true under the circumstance where corruption is initially overwhelming (i.e. the initial $\tau$ is greater).

\section{CONCLUSIONS}

In a way that departs from the traditional framework, this article has developed a more general model in which individual and organized crime are coexisting alternatives from which a potential offender can choose. Based on this framework, we are able to analyze the interactive relationships among individuals' choices of crimes, the market structure for crimes, the government's law enforcement strategies, and the aggregate crime rate.

The article has considered two different sharing schemes - the uniform and abilityadherent sharing schemes-for Mafia members. Under the uniform-sharing scheme, if the Mafia cannot provide any extra benefit for its members, then the so-called free-rider problem will choke off any incentive to join the Mafia. As a result, the criminal market will turn out to be perfectly competitive, and all offenders will become individual criminals. Even if it is able to provide positive extra benefits to its members, the Mafia will only entice offenders with relatively low criminal skills to join the organization. The potential offenders who are highly skilled will tend to commit crimes alone. The market structure for crimes will thus exhibit the $[N, O, I]$ equilibrium. Given this equilibrium, we have shown that when the Mafia creates a larger extra benefit for its members, the equilibrium crime rate will rise in response. Furthermore, in the presence of a positive Mafia extra, the existence of the Mafia may not be welfare-improving.

Under the ability-adherent sharing scheme, the criminal market may end up with a very different market structure. By extending the benchmark model, we have proved the existence of a distinctive equilibrium, namely, the $[N, I, O]$ equilibrium. This implies that 
the Mafia can entice potential offenders who have high criminal skills to join the organization, as the Mafia's payoff is distributed according to members' abilities. Given the different sharing schemes within criminal organizations, the article potentially provides an explanation for Anderson's observation that there are considerable variations in personal qualities and values across different criminal organizations.

Some assumptions in this article are still debatable and should be extensively discussed in future research. First, under the abilityadherent sharing scheme, section IV focused on the existence of the $[N, I, O]$ equilibrium, whereas we have not tackled the relevant issues concerned with the crime rate and the government's optimal law enforcement under different $[N, I, O]$ and $[N, O, I]$ equilibria. It is interesting to investigate these issues and compare the consequences under two distinctive equilibria. For a preliminary discussion, one may refer to the working paper by Chang et al. (2002). Second, we have described the interaction between the government and the Mafia by a Cournot-Nash game. However, it may be a case where the government and the Mafia play a Stackelberg game instead. Along this line, it may be also interesting to extend the model to compares the equilibrium solutions under different games (including Cournot-Nash and Stackelberg games) and different market structures (including perfect competition, monopoly, and self-selection markets). For the relevant discussions, readers is also referred to our working paper. Third, in this article the Mafia's extra benefits have been endogenized and are related to the members' average ability within the organization (in the benchmark) and the government's law enforcement (in the extension). Nevertheless, here we do not formally take account of how the criminal organization runs its business. Garoupa (2001) sets up a principal-agent model to analyze how the principal (the leader of the criminal organization) provides extra information to his members. By means of a monopolistic competition model, Kugler et al. (2003) address the issue of how the criminal organizations compete with each other in relation to the crime and corruption. Following this line of research, it would also be worthwhile in our future research to engage in a relevant extension. To seriously deal with this issue, more sophisticated analysis concerned with the interaction between a government and the Mafia is needed.

\section{APPENDIX A: PROOF OF PROPOSITION 4}

Define $\Psi \equiv \alpha^{3} \theta+3 \alpha^{2} \theta-\alpha+1$ and hence $\Psi_{\alpha} \equiv \partial \Psi /$ $\partial \alpha=3 \alpha^{2} \theta+6 \alpha \theta-1$. To guarantee $R>0$, we should also restrict $\Psi>0$. With this restriction, from (20), we have

$$
\begin{aligned}
\partial R / \partial \alpha= & \left\{[ \Psi / ( 1 - \alpha ) + \Psi _ { \alpha } ] \left[(1+\alpha) h_{2}\right.\right. \\
& \left.-2 \alpha h_{1}-(1+\alpha) c / F\right] \\
& \left.+2 \Psi\left(h_{1}-h_{2}+c / F\right) /(1-\alpha)\right\} / \Psi^{2}
\end{aligned}
$$

In (A1) when we restrict the law enforcement $p^{*} f^{*}>0$, $-2 \alpha h_{1}+(1+\alpha) h_{2}-(1+\alpha) c / F>0$ must be met. Furthermore, because $\alpha$ and $\theta$ are less than 1 , then

$$
\Psi /(1-\alpha)+\Psi_{\alpha}=2 \alpha \theta\left(3-\alpha^{2}\right) /(1-\alpha)>0 .
$$

These conditions allow us to conclude $\partial R / \partial \alpha>0$, meaning that, as $\alpha$ increases, the equilibrium crime rate will rise as a response. In addition, from (19) we have

$$
\begin{aligned}
R_{O} & =b_{u}^{*}-b_{l}^{*} \\
& =\alpha\left[-2 \alpha h_{1}+(1+\alpha) h_{2}-(1+\alpha) c / F\right] / \Psi
\end{aligned}
$$

According to (A2), the comparative static concerning $R$ with respect to $\alpha$ is given by

$$
\begin{aligned}
\partial R_{O} / \partial \alpha= & \left\{\left(\Psi-\alpha \Psi_{\alpha}\right)\right. \\
& \cdot\left[-2 \alpha h_{1}+(1+\alpha) h_{2}-(1+\alpha) c / F\right] \\
& \left.-\alpha \Psi\left[2 h_{1}-h_{2}+c / F\right]\right\} / \Psi^{2} \gtreqless 0
\end{aligned}
$$

Q.E.D.

\section{APPENDIX B: PROOF OF PROPOSITION 5}

Consider two potential offenders with criminal rents $b_{u}$ and $b_{u}+\varepsilon$, where $\varepsilon \rightarrow 0^{+}$. According to self-selection constraint and (21), the existence of $[N, I, O]$ must satisfy:

$$
\begin{aligned}
& (1+\alpha) R\left(b_{u}\right)\left(1+b_{u}\right) / 2-y-p f_{1} \leq b_{u}-p f_{2} \\
& \quad \Rightarrow \Phi\left(b_{u} ; \alpha\right) \leq y+p \cdot \Delta f \text { and } \\
& (1+\alpha) R\left(b_{u}+\varepsilon\right)\left(1+b_{u}+\varepsilon\right) / 2-y-p f_{1}>b_{u}-p f_{2}+\varepsilon \\
& \quad \Rightarrow \Phi\left(b_{u}+\varepsilon ; \alpha\right)>y+p \cdot \Delta f
\end{aligned}
$$

These conditions indicate that $\Phi\left(b_{u}+\varepsilon ; \alpha\right)>\Phi\left(b_{u} ; \alpha\right)$, implying that $\partial \Phi /\left.\partial b\right|_{b=b_{u}}>0$. Because $y+p \cdot \Delta f>0$, we also need the condition $\Phi(b ; \alpha)>0, \forall b \in\left(b_{u}, 1\right]$. That is, the Mafia must provide a large enough $\alpha$ to ensure the existence of the equilibrium $[N, I, O]$. If the extra benefit effect is so small that $\Phi(b ; \alpha)<0 \forall b$, then we cannot find a critical value $b_{u} \in\left(p f_{1}, 1\right]$.

Q.E.D.

\section{REFERENCES}

Abadinsky, H. Organized Crime, 4th ed. Chicago: Nelson Hall, 1994. 
Anderson, A. "Organized Crime, Mafia and Governments," in The Economics of Organized Crime, edited by G. Fiorentini and S. Peltzman. Cambridge: Cambridge University Press and CEPR, 1995, 33-54.

Backhaus, J. "Defending Organized Crime? A Note." Journal of Legal Studies, 8, 1979, 623-31.

Becker, G. "Crime and Punishment: An Economic Analysis." Journal of Political Economy, 76(2), 1968, $169-217$.

Buchanan, J. M. "A Defense of Organized Crime?" in The Economics of Crime and Punishment, edited by S. Rottenberg. Washington, DC: American Enterprise Institute, 1973, 119-32.

Chang, J. J., C. C. Lai, and C. C. Yang. "Casual Police Corruption and the Economics of Crime: Further Results." International Review of Law and Economics, 20(1), 2000, 35-51.

Chang, J. J., H. C. Lu, and M. Chen. "Organized Crime or Individual Crime? Endogenous Size of a Criminal Organization and the Optimal Law Enforcement." Working Paper, Academia Sinica, 2002.

Dick, A. R. "When Does Organized Crime Pay? A Transaction Cost Analysis." International Review of Law and Economics, 15(1), 1995, 25-45.

Fiorentini, G., and S. Peltzman. "Introduction," in The Economics of Organized Crime, edited by G. Fiorentini and S. Peltzman. Cambridge: Cambridge University Press and CEPR, 1995, 1-30.

Gambetta, D., and P. Reuter. "Conspiracy among the Many: The Mafia in Legitimate Industries," in The Economics of Organized Crime, edited by G. Fiorentini and S. Peltzman. Cambridge: Cambridge University Press and CEPR, 1995, 116-36.

Garoupa, N. "The Economics of Organized Crime and Optimal Law Enforcement." Economic Inquiry, 38(2), 2000, 278-88.

_. "Optimal Law Enforcement and Criminal Organization." Manuscript, Universitat Pompeu Fabra, 2001.

Grossman, H. I. "A General Equilibrium Model of Insurrections." American Economic Review 81(4), 1991, 912-21.

- "Rival Kleptocrates: The Mafia versus the State," in The Economics of Organized Crime, edited by G. Fiorentini and S. Peltzman. Cambridge: Cambridge University Press and CEPR, 1995, $143-56$.

Hirshleifer, J. "The Paradox of Power." Economics and Politics, 3(3), 1991, 177-200.
Johnson, E. "Organized Crime: Challenge to the American Legal System, Part I." Journal of Criminal Law ad Criminology, 53(4), 1962, 399-425.

Klein, M. W., and L. Y. Crawford. "Groups, Gangs, and Cohesiveness." Journal of Research in Crime and Delinquency, 41, 1967, 63-75.

Kugler, M., T. Verdier, andV. Zenou. "Organized Crime, Corruption and Punishment." CEPR Discussion Paper No. 3806, 2003.

Morash, M. "Gangs, Groups, and Delinquency." British Journal of Criminology, 23(4), 1983, 309-35.

Polo, M. "Internal Cohesion and Competition among Criminal Organizations," in The Economics of Organized Crime, edited by G. Fiorentini and S. Peltzman. Cambridge: Cambridge University Press and CEPR, 1995, 87-109.

Posner, R. Economic Analysis of Law, 5th ed. New York: Aspen Law and Business, 1998.

Reiss, A. J. Jr. "Why are Communities Important in Understanding Crime?" in Communities and Crime: Crime and Justice: A Review of Research, vol. 8, edited by A. J. Reiss Jr. and M. Tonry. Chicago: University of Chicago Press, 1986, 432-56.

Rubin, P. H. "The Economic Theory of the Criminal Firm," in The Economics of Crime and Punishment, edited by S. Rottenberg. Washington, DC: American Enterprise Institute, 1973, 155-66.

Sarnecki, J. Delinquent Networks. Stockholm: National Council for Crime Prevention, 1986.

Schelling, T. S. The Strategy of Conflict. Cambridge, MA: Harvard University Press, 1960.

_. "Economics and the Criminal Enterprise." Public Interest, 7, 1967, 61-78.

Skaperdas, S. "Cooperation, Conflict and Power in the Absence of Property Rights." American Economic Review, 82(4), 1992, 720-39.

Skaperdas, S., and C. Syropoulos. "Gangs as Primitive States," in The Economics of Organized Crime, edited by G. Fiorentini and S. Peltzman. Cambridge: Cambridge University Press and CEPR, 1995, 61-82.

Tullock, G. The Social Dilemma: The Economics of War and Revolution. Blacksburg: Virginia University Publications, 1974.

Williamson, O. E. "Transaction Cost Economics: The Governance of Contractual Relocations." Journal of Law and Economics, 22(2), 1979, 233-61.

. The Economic Institutions of Capitalism: Firms, Markets, Relational Contracting. New York: Free Press, 1985. 